\title{
Exploring the Integration of Near-Death Experience Aftereffects: Summary of Findings
}

\author{
Ryan A. Rominger, Ph.D. \\ Institute of Transpersonal Psychology, Palo Alto, CA
}

ABSTRACT: Preliminary evidence suggests that both near-death experiencers (NDErs) and nonexperiencers who learn about near-death experiences (NDEs) show beneficial aftereffects. In this article I summarize the findings of an exploratory study to examine a small group process utilizing spiritual guidance and expressive arts for integrating NDE aftereffects. Eleven adult participants - four NDErs and seven non-NDErs - completed a pretest, initial posttest, and longitudinal posttest consisting of a revised version of the Omega Life Change Questionnaire (Rominger-LCQ) and the Human Spirituality Scale, as well as semistructured individual and group interviews. I also collected the expressive art participants created during sessions, photographed it, and used it to identify pictorial themes.

Quantitative results included some significant differences and some nonsignificant trends indicating greater spirituality and life changes among NDErs compared to non-NDErs and, for all participants, from pre- to posttest. Qualitative interview material revealed participants had learned material on a number of topics including a broader understanding of, and ability to communicate about, the NDE. Qualitative pictorial data revealed themes suggesting that both NDErs and non-NDErs had integrated positive aftereffects.

The process described herein may benefit spiritual guides and directors, expressive art therapists, and therapists working with individuals who have had an NDE or other spiritually transformative experience. I also discuss methodological benefits of using artistic inquiry.

KEY WORDS: near-death experience aftereffects; integration; spirituality; artistic inquiry; small group process.

Ryan A. Rominger, Ph.D., is a Global Core Faculty member and Associate Dissertation Director at the Institute of Transpersonal Psychology in Palo Alto, CA. Reprint requests should be addressed to Dr. Rominger at the Institute of Transpersonal Psychology, 1069 E. Meadow Circle, Palo Alto, CA 94303; e-mail: rrominger@itp.edu. 
The present study was an inquiry into the aftereffects of the neardeath experience (NDE). Specifically, in this study I explored aspects of integrating the aftereffects of the NDE in near-death experiencers (NDErs) and non-NDErs. NDEs have been found most commonly in people who have either clinically died or come close to physical death (Grosso, 1981) with incidence of NDEs ranging from $42 \%$ of individuals close to death due to illness (Ring, 1980) to 6\% of cardiac arrest patients (Parnia, Waller, Yeates, \& Fenwick, 2001). Based on estimates (Gallup \& Proctor, 1982; see also Famighetti \& McGeverainder, 2000; U.S. Census Bureau, 2000), by 2006 roughly 15.4 million individuals would have had an anomalous experience around death. Although the exact number of NDErs in the U.S. and worldwide cannot be known, it is undoubtedly in the millions.

The NDE has been found typically to generate some form of transformation within the experiencer. NDErs have been found to fear death less; to have less death threat; to have less suicidal ideation; to be more spiritual and less religious; to have an increased sense of purpose and meaning in life; to have an increased appreciation for life; to have greater compassion for others, the environment, and themselves; and to show a myriad of other changes in values and beliefs (Dougherty, 1990; Greyson, 1992, 1993b, 1996, 1997, 2006; Greyson \& Bush, 1992; Groth-Marnat \& Summers, 1998; Kellehear, 1990; Moody, 1975; Musgrave, 1997; Ring, 1984a, 1995; Ring \& Valarino, 1998; White, 1997).

Most of the above aftereffects would seem to indicate a greater ease to living life. However, Bruce Greyson (1994) reported that NDErs do not have a higher satisfaction with life. He speculated that this finding might be due to NDErs' difficulties adjusting to life after their experience, especially because, as Michael Grosso (1981) noted, NDErs "are often unable to share their experiences and even fear for their sanity" (p. 9). Additionally, negative aftereffects have been noted as an apparent result of near-death phenomena. Partially, they include the dramatic changes required for integration of the pleasurable aftereffects heretofore mentioned. Aftereffects have also been reported following distressing NDEs. Greyson and Nancy Evans Bush (1992) reported that a distressing experience can leave an individual with a "pervasive sense of emptiness and fatalistic despair" (p. 104) or with a decreased desire to talk with anyone because of the belief that no one else existed. Additionally, those who do have distressing experiences may be even more inclined to suppress the experience and not talk 
about it out of fear of it being dismissed or, worse yet, considered a sign of mental illness.

NDErs are not the only people who may be transformed from the retelling of the NDE. Kenneth Ring (1995; Ring \& Valarino, 1998) reported that individuals who learn about NDEs are themselves positively changed in much the same manner as NDErs. Linda Morris and Kathleen Knafl (2003) found similar effects among nurses in critical care units: Nurses who encountered patients who reported NDEs or who had an anomalous experience themselves reported feeling more compassion and understanding, were more comfortable talking about death, and felt a closer relationship with God. Allan Kellehear's (1990) findings supported this effect, but from a different viewpoint. He believed that the NDE is a social status rite of passage with the possibility to create social change in those who hear and learn about the NDE. Ring (1995) believed that the most influential factor of nonexperiencer transformation was hearing first person accounts from NDErs. Additional research in the area of transformation within the non-NDEr population is scarce; however, research on the attitudes and knowledge of certain groups may be pertinent to the current review. Research with helping professionals has repeatedly demonstrated a positive correlation between knowledge of neardeath phenomena and positive attitudes toward the NDEr and/or the experience (Bechtel, Chen, \& Pierce, 1992; Hayes \& Waters, 1989; Ketzenberger \& Keim, 2001; Royse, 1985; Walker \& Russell, 1989).

In this study, I posed a method of working with the NDE and nonNDE population that included spiritual guidance and expressive arts in a group format. Spiritual guidance, or spiritual companioning, is a form of psychospiritual work in which the emphasis is on an individual's or a group's spiritual development. The goal is the cultivation of the spiritual life of the inquirer (Hardy, 2000). Expressive arts, also called creative expression, is another means of potential transformation and integration. Creative expression, like spiritual guidance, can be conducted with individuals or with groups, and it emphasizes nonverbal means of expression, such as working with clay, chalk and oil pastel painting, and collage (Rogers, 1993). Creative expression can also emphasize creative verbal modes of expression, such as writing or speaking poetry, doing improvisational dialogue and movement, or journaling (Rogers, 1993). In this study, the mediums I offered participants included oil and chalk pastels, 
tempera paints, and charcoal on paper. I hypothesized that when an NDEr was able to share one's experience both verbally and nonverbally within a sacred, safe, contained environment, the individual would feel truly "heard" and might more fully integrate the NDE. When a person feels heard around a particular issue or event, integration of that experience may occur (Rogers, 1993). Similarly, I hypothesized that the non-NDErs within the group would, through hearing the NDE narrative, learn about the NDE and its aftereffects.

\section{Purpose and Method}

The purpose of this study was to investigate the integration of NDE aftereffects into the lives of both NDErs and non-NDErs as a result of using group spiritual guidance and creative expression. I believed that together spiritual guidance and creative expression would constitute a strong, safe psychological container for NDErs to tell their personal NDE narratives and for both NDErs and non-NDErs to develop psychospiritually.

\section{Quantitative Design Specifications}

Quantitative data collection occurred over a 12 -week period. In the first week, participants received pretest $(\mathrm{P})$ materials by mail and were encouraged to return materials by the start of the first small group meeting. Participants then attended four meetings over the next five weeks with a one-week break half way through the sessions. In week seven, participants attended a group interview, at the end of which they received initial posttest (P1) materials with instructions to return completed materials by mail within one week. In week 12, participants received final, longitudinal posttest (P2) materials by mail, again with instructions to return completed materials by mail.

\section{Measurement Characteristics}

One of the two quantitative measures I used in this study, the Human Spirituality Scale (HSS), is a 23-question pencil-and-paper, self-report assessment based on a 5-point Likert scale measuring spirituality from a nondenominational perspective. It exhibited both 
high content validity as rated by an independent panel of five judges and high reliability as measured by Cronbach's alpha $(\alpha=0.89$; Wheat, 1991). Luther Wheat (1991) conducted three studies using this measure and believed these studies gave ample support to his claim of high construct validity for the HSS.

The other measure was the Life Changes Questionnaire (LCQ), a questionnaire Ring (1984a) created to determine how individuals' beliefs and values had changed following a specific event or time frame. The LCQ is a 42-item self-report pencil and paper measure with five clusters: Appreciation of Life, Concern for Others, Concern with Impressing Others, Materialism, and Quest for Meaning (Ring, 1984a). Each item indicates a phenomenon for which the respondent chooses either strongly increased, increased, not changed, decreased, or strongly decreased.

I added five items to the LCQ (Ring, 1984a) that directly asked participants about their sexuality. According to Jann Devereux (1995), individuals' sexuality may change after encountering a mystical "light" such as that in the NDE. The five additional items were:

My sexual energy has...

My desire for a variety of sexual experiences has...

My feelings of intimate connection and unity with my sexual partner during our sexual encounters have...

The intensity of my sexual experiences has...

The sacredness of my sexual experiences has....

Because Greyson and Ring (2004) published a revised version of the LCQ as the Life Changes Inventory - Revised (LCI-R), to avoid confusion I refer to my revision of the LCQ as the RomingerLCQ.

Ring (1984a) did not report reliability assessment of the LCQ. However, a post hoc Cronbach's alpha of the Rominger-LCQ I computed yielded an alpha score of .86 indicating high reliability. It seems apparent that addition of the sexuality questions did not adversely affect the measure's reliability.

Regarding validity, Ring determined that external behavioral validation offered strong confirmation of NDErs' LCQ self-reports, although he did not collect enough data for statistical analysis. At a minimum, the LCQ seemed to uphold content validity. Furthermore, several researchers have used the LCQ, especially in studies of NDErs (for example, Groth-Marnat \& Summers, 1998). The Rominger-LCQ, 
though, has not been tested for validity, and it is possible that the addition of the above six sexuality questions decreased the instrument's validity.

For the pretest, NDE participants were invited to answer questions by comparing their lives since their NDEs to their lives before their NDEs. During the informed consent process, NDErs had indicated the lapsed time since their NDEs; I calculated the mean elapsed time as 28 years. I asked non-NDE participants to answer questions by comparing their lives prior to that point in time to their lives since that point in time. For the initial posttest, I asked all participants to reflect upon the past 5 weeks - the small group phase when completing the measure. For the final posttest, I asked all participants to reflect upon the previous 11 weeks since the beginning of the study.

To measure the presence of an NDE, all participants completed Greyson's (1983) NDE Scale. The NDE Scale is a self-report, penciland-paper measure with 16 multiple-choice questions. Internal consistency for determining presence of near-death attributes, determined by Cronbach's alpha, was .88, and total reliability for the NDE Scale, after applying split-half and time sampling measures, was .92 (Greyson, 1983). Greyson determined criterion validity by correlating the NDE Scale with Ring's (1980) Weighted Core Experience Index, a previously published scale that measures depth of NDEs; the resulting correlation was high $(r=.90)$. Thus, Greyson's (1983) NDE Scale has high reliability and validity.

My original intention was to use Greyson's (1983) cutoff score of at least 7 as indicating the presence of an NDE, scores below 4 as indicating the absence of an NDE, and scores of 4-6 as indicating too few elements to conclude the presence of an NDE but too many to conclude absolute absence. However, due to variance in the NDE phenomenon, including distressing NDEs, I considered NDErs to be not only the high scorers on the NDE Scale $(n=5)$ but also one individual who, when screened through phone conversations, reported a distressing NDE that the NDE Scale score had not captured because the Scale assesses predominantly pleasurable NDE features. These six participants constituted the NDEr group. Similarly, some non-NDErs had had mystical or nonordinary experiences outside the context of a near-death situation; although some of these individuals scored more than 4 points on the NDE Scale, I included them in the non-NDEr group. 


\section{Qualitative Design Specifications}

The qualitative measures of this study were two-part. First, I gathered qualitative data using a semistructured interview format. Participants met for a semistructured group interview one week following the fourth session. This group interview lasted approximately one hour. Within a week after the group interview, I conducted an individual semistructured interview with each participant. Each individual interview lasted approximately one hour. I recorded all interviews with a tape recorder, transcribed each interview, and analyzed all transcriptions using aspects of intuitive inquiry (Anderson, 1998, 2000). Analysis included inputting transcribed data into HyperRESEARCH, a qualitative research program. I then reviewed the data multiple times, collecting and refining themes and codes through each successive analysis. During this process, I analyzed the data for pertinent information relating to the effectiveness of the small group phase.

The second qualitative aspect of this study was an intuitive inquiry and artistic inquiry design utilizing both my analysis and reflections from three resonance panels. The first panel consisted of two NDErs, the second panel four professional spiritual guides/directors, and the third panel three professional expressive artists/expressive art therapists. I recruited members for each group from professional organizations through the use of letters, phone calls, email, and word of mouth. Each panel met for 1-1.5 hours, and members were invited to respond to a series of questions regarding visual themes found within the photographs. The NDE resonance panel knew the topic before meeting, whereas the other two panels did not know the topic of the study until after responses were provided and, thus, were blind to the topic. Responses were recorded and compared among the groups and to the themes I had generated.

\section{Participants}

Participants were recruited by various means throughout the San Francisco Bay area. Recruitment strategies included an announcement in the local newspaper (8 participants), a verbal announcement at an Institute of Noetic Sciences (IONS) meeting (1 participant), word of mouth (1 participant), and announcements and flyer distribution at local meetings of the Friends of the International Association for NearDeath Studies (IANDS; 1 participant). All participants were self- 
selected, and no inquirers were excluded due to screening. Additionally, two female NDErs started the groups and withdrew before completing the small group process. Once an individual answered the invitation to participate, a screening process ensued. Participants were sent a cover letter requesting completion of the NDE Scale (Greyson, 1983) and consent form and were asked to return the completed materials via mail. Due to minimal response, participants were placed in groups on a first-come basis, with groups starting if at least three individuals, comprised of at least one NDEr and one nonNDEr, were signed up for the group.

Participants' ages ranged from 31 to 80 years old with an average age of 49. Eight participants were Caucasian, one Indonesian, one multi-racial Mexican-American, and one self-identified as Other. Three individuals were Catholic, one Christian mystic, one Eckankar, one Jewish, and one Methodist. One reported being Catholic by birth but now practicing Protestantism, Islam, Hinduism, and Buddhism; another a combination of Catholicism and Paganism; another Protestant and Buddhist; and one did not report a religious affiliation. The average education level was between a college degree and some graduate school, with four individuals having completed some college, one a college degree, one some graduate school, three a master's degree, and two a doctoral level degree. Four participants entered and completed the groups knowing that they had had an NDE. Average elapsed time since the NDEs was 27.85 years, with one individual's having occurred months prior and the other three's having occurred between 33 and 36 years prior to the study. After the group meetings commenced, one participant discovered she had had an empathic NDE (Moody, 1999) during her 20s that she had not classified as such prior to the study. Five participants knew of a family member, and seven knew of a friend, who had had an NDE. All individuals had read of the NDE in books or research articles, five had heard of the NDE from NDErs, five from friends, four through movies, two from family members, and one during a graduate school event.

When asked what inner work participants were currently practicing, five reported spiritual guidance, five reported meditation, four reported speaking with religious clergy or leaders, four reported reading various literature, three reported individual therapy, three reported speaking with a medical doctor, two reported using expressive arts, and one each reported group therapy, attending IANDS meetings, speaking with a nurse or other medical personnel, 
speaking with other NDErs, yoga, and dream work. Those individuals who had had an NDE were asked what methods they had used to adjust to the aftereffects of the NDE. Three reported attending spiritual guidance sessions, two reported individual therapy, and one each reported attending IANDS meetings, speaking with religious clergy or leaders, speaking with a medical doctor, meeting with other NDErs, meeting with a psychic medium, and reading.

Each participant completed four sessions in one of three groups. Two participants completed the first group, three completed the second group, and six completed the third group. I combined the data for the three groups to form one set of pretest $(\mathrm{P})$, posttest one (P1), and posttest two (longitudinal posttest; P2) measures. Group 1 consisted of one female core NDEr who dropped, one male individual who had a distressing NDE, one female non-NDEr who discovered she had had an empathic NDE, and myself as the facilitator. Group 2 consisted of one female core NDEr who moved to group three after participating in the first two sessions, one male core NDEr, one male and one female non-NDEr, and myself as the facilitator. Group 3 consisted of one female core NDEr who had dropped from group two after the first two meetings, two core female NDErs, two female nonNDErs, two male non-NDErs, and myself as facilitator.

\section{Procedure}

Participants received the pretest measures through U.S. mail one week before the start of the group meetings; through the enclosed instructions, I asked them to bring their completed pretest measures to the first session. To protect participants' confidentiality, I then assigned each participant a number that I used to code pretests and all subsequent materials including photographed artwork.

Each of the four sessions lasted approximately 2.5 hours, starting with a small ritual (bell, meditation, quiet time, visualization, etc.) and proceeding with a check-in for the participants. From this point on, NDErs gave "voice," both verbally and nonverbally, to their experiences, and non-NDErs listened and reflected upon, verbally and nonverbally, the NDErs' experiences, their own experiences, and their reactions to hearing the NDE narratives. Because of the uniqueness of each NDEr's narrative, the exact contents of each session was unique. During the final hour of each session, I invited each participant to create a visual creative expression in response to the session. At the 
end of each session, each participant set out one's visual creative expression(s), and I took pictures of each piece with the participant's number on the bottom right corner for coding purposes. The camera was a digital camera; all pictures were kept confidential and processed using digital technology and computer programs on a home computer system. I printed one set of each participant's pictures for the last (fourth) session's exercise. I printed a second set for each participant to have during the interview process.

I scored participants' pretest and posttest measures and, when necessary, entered scores into an SPSS or Excel file to conduct the relevant statistical analysis. I transcribed interview recordings and entered the transcripts into HyperRESEARCH for analysis.

I used the Wilcoxon Matched-Pairs test for within group comparisons on pre-post measures ( $\mathrm{P}$ to $\mathrm{P} 1$ ) and longitudinal measures ( $\mathrm{P} 1$ to $\mathrm{P} 2$ and $\mathrm{P}$ to $\mathrm{P} 2$ ). I conducted additional post hoc analyses, including the Kruskal-Wallis test and Crosstabs that utilize the chi-square analysis for difference. I also used a one-sample $t$ test for comparison to normative data on the HSS.

I conducted qualitative analysis in stages. In the first stage I listened to all interviews while reading the textual transcription. During this process I wrote down recurring themes that became apparent. I then analyzed transcripts using HyperRESEARCH. As I re-read the transcripts in this program, I coded sections of the transcript electronically. The program kept track of codes, coded material, and text. Then, for themes or codes that seemed vague, I printed them out for further analysis. I further analyzed this coded material by hand through the re-reading of the data and differentiating minor themes within each code. Finally, I created a list of codes, ran a frequency of codes, and highlighted coded data from the printouts as exemplars of each code.

Simultaneously, I performed a visual content analysis on the visual expressive art pieces the participants had created. First, I viewed all photographs and searched for visual themes within the pictures: recurring themes, images, color combinations, or absences of content. Second, I viewed the pictures for each group of either NDErs or non-NDErs, looking for the same visual themes as they compared within and between the groups. Finally, I separated pictures per session and searched for visual themes relating to session topics. I also analyzed for differences among pictures created in different sessions. 
The three resonance panels then viewed the photographs of the expressive art. I asked each panel to reply individually and collectively to a series of questions including (a) Can you differentiate between the two groups within the study? and (b) What are the main themes that you see present within the pictures? I compared the panel's responses to the actual listing of which participants were NDErs and which were not to determine the accuracy of the panel's choices. Additionally, I asked the NDE resonance panel (the only panel to know the topic under study) to pick three to five pictures out of all of the pictures that most represented (a) the NDE, and (b) the aftereffects of the NDE. I told panel members that the pictures may represent the experience thematically, may represent it by including a representation of some subjective state, or may just resonate with the panel member for no particular reason. I then compared themes the various panels had generated to each other and to the qualitative codes I had established.

\section{Results}

Due to the enormous amount of data collected during this study and the many types of analysis, only a portion of the study results are presented here. Several main aspects of the study are reported below. Some of these aspects focus on the differences and similarities found between the NDE and non-NDE subgroups, whereas others focus on the potential change that may have occurred during the spiritual guidance and expressive arts sessions. All of the findings reported have been deemed "significant," either clinically or statistically, within the study. For full results, see Rominger (2004).

\section{Quantitative}

Human Spirituality Scale. For all participants combined $(N=11)$, the Wilcoxon Signed Ranks test revealed three significant findings. P1 mean scores were significantly higher than $\mathrm{P}$ means on experiencing a sense of connection with other living things $(z=-2.45, p<.01)$, finding meaning in life by creating close relationships $(z=-2.12, p<$ $.04)$, and reading articles on health and inner peace $(z=-2.24, p<$ .03 ), indicating an increase in these three phenomena. Means at all three assessment points $-\mathrm{P}, \mathrm{P} 1$, and $\mathrm{P} 2$ - graphically represented as an inverted V. Thus, P1 means were significantly greater than $\mathrm{P}$ 
means, but $\mathrm{P} 2$ means were greater but not significantly greater than $\mathrm{P}$ means.

A comparison of subgroups revealed that NDErs $(n=4)$ had higher, but not significantly higher, total average mean scores compared to non-NDErs $(n=7)$ at $\mathrm{P}(M=88.75$ vs. 76.86$)$, at $\mathrm{P} 1(M=91.25$ vs. $83.14)$, and at P2 ( $M=88.75$ vs. 82.86$)$. To identify specific items involved in these differences, I used chi-square Crosstabs tests. At P, NDErs scored significantly higher on valuing the relationship between all living things, putting the interests of others before one's own interests when making a decision, and actively seeking a sense of purpose in life. At P1, NDErs scored significantly higher on experiencing a sense of the sacred in living things, experiencing a sense of connection with other living things, and finding meaning in life by creating close relationships, and at P2 on experiencing a sense of connection with other living things. However, when I applied a Bonferonni correction for simultaneous statistics (Weisstein, 2004) to reduce Type 1 error, all Crosstabs significances fell within chance. Thus, these results should be viewed as possible trends rather than statistical certainties.

Finally, I analyzed the HSS using a post hoc $t$ test against the normative means provided by the author of the measure (Wheat, 1991, p. 71). Wheat administered the final version of the HSS to three distinct and separate groups: a group of individuals meeting "in formal, long term spiritual formation groups" (p. 69) here called the high spirituality group; a group of 246 people sunbathing on a beach, here called sunbathers; and a voluntary group of 39 incarcerated individuals, here called the jailed group. The total HSS score was averaged for each participant in the present study, and those scores were averaged and analyzed against Wheat's three groups' total score means. The means of all participants in this study $(\mathrm{N}=11)$ at all three measurement points $-\mathrm{P}(M=81.18), \mathrm{P} 1(M=86.09)$, and $\mathrm{P} 2(M=$ $85.00)$ - were significantly greater than the jailed group mean $(M=$ $73.62 ; p<.03, p<.01, p<.01$, respectively). Participants' P mean ( $M$ $=81.18$ ) was not significantly different from the sunbathing group mean $(M=79.31 ; p=.53)$, but participants' means at both $\mathrm{P} 1(M=$ $86.09 ; p<.01)$ and $\mathrm{P} 2(M=85 ; p<.01)$ were significantly greater. When compared to the high spirituality group $(M=82.26)$, participants' means at neither $\mathrm{P}(M=81.18 ; p=.72)$ nor P2 $(M=$ $85 ; p=.11)$ was significantly different, but their mean at P1 was significantly greater $(M=86.09 ; p<.05)$. 
Rominger-LCQ. One important aspect of the Rominger-LCQ is that the pretest focused on a period of either (a) for NDErs, since the NDE, or (b) for non-NDErs, since 28 years ago - the average time since NDE for NDErs. The posttests, however, focused on the time from the start of the sessions, asking participant to answer based on the previous five weeks (P1) or on the previous 11 weeks (P2). This difference in focus does not allow (as previously thought, see Rominger, 2004) a direct comparison of pretest to posttests to determine change. However, it does allow comparison between how a person reportedly felt they had changed over the past 28 years or since an NDE and how a person reportedly felt they had changed since the start of the study. In many cases participants reported having changed as much since the start of the group experience as they had originally reported having changed since their NDEs or since 28 years ago.

As a reminder, response options ranged from strongly increased $=1$, to not changed $=3$, to strongly decreased $=5$. Those items in which all participants $(N=11)$ demonstrated the lowest scores $(1-2)$ on average at $\mathrm{P} 1$ and P2, indicating strongly increased to increased, were: my desire to help others, my compassion for others, my appreciation of "the ordinary things of life," my interest in psychic phenomena, my concern with spiritual matters, my understanding of myself, my desire to achieve a higher consciousness, my appreciation of nature, my understanding of "what life is all about," my personal sense of purpose in life, my sense of the sacred aspect of life, my sense that there is some inner meaning to my life, my interest in self-understanding, my inner sense of God's presence, my conviction that there is life after death, my search for personal meaning, and my interest in issues related to death and dying. Those items that had scores between 3 and 4 at P1 and P2, indicating some decrease, were: my concern with the material things of life, my interest in creating a "good impression," my interest in organized religion, my ambitions to achieve a high standard of living, my fear of death, my desire to become a well known person, and my interest in what others think of me. Similarly, a Spearman's Rho run on the P, P1, and P2 RomingerLCQ data revealed a pattern of positive correlation on the subcategories of appreciation of life, concern for others, and a quest for meaning. Thus, an increase in each corresponded to a similar increase in the others.

A Wilcoxon Signed Ranks test run on the Rominger-LCQ data revealed several significant differences. However, a Bonferonni 
correction for multiple statistics indicated that significance scores were not more than those attributed to chance. Chi-square analysis for difference between groups also initially revealed several significant differences between the NDE and non-NDE subgroups. Again, a Bonferonni correction demonstrated these differences to be within the realm of chance. However, these differences are still worth mentioning as trends within the data. At pretest, compared to NDErs, non-NDErs had higher mean scores, indicating decreased, not changed, or a lesser increased on three items: understanding of "what life is all about," having a sense of the sacred aspect of life, and acceptance of others. At P1, non-NDErs had higher mean scores on four items: feelings of intimate connection, unity with a partner during sexual encounters, tendency to pray, and interest in self-understanding. With both statistical analyses, the two groups showed no significant differences at P2.

\section{Qualitative Themes}

During analysis many themes emerged from interview material. The first two themes presented, learnt from listening and sharing and learnt from drawing, were not specifically divided between NDE responses and non-NDE responses. The remaining three themes, changes because of the group, changes in perspective toward the NDE, and new or unusual "stuff" that came up during the groups, were divided between NDE and non-NDE responses, indicating different reactions to the group process.

Learnt by listening and sharing. Generally this theme can be divided into two areas: listening and sharing. Listening can again be divided into learning about oneself through listening and learning about others through listening. A vast majority of what was learnt when an individual shared pertained to self-perceptions.

The areas contained within the subdivided area learnt about oneself through listening to the group conversations were: learnt about own NDE and its aftereffects, increased meaningfulness/purpose/reason in life, increased connection with self and others, learnt about love and acceptance, broadening/expansion of self and understanding of the $\mathrm{NDE}$, interest/acceptance/reverence for own transformation, increased awareness of annoyance/frustration at "floundering" of others, increased questioning, and a sense of validation and confirmation of own experience. For example, Pebble, a non-NDEr, said of her 
learning, "I learned more about near-death experiences, and I learned about other things I didn't know I wanted to learn about that are related to near-death experiences, sort of content learning." Tina, a woman who entered the study as a non-NDEr, said of her empathic NDE, "I didn't even know mine was a near-death experience...." Luke, an NDEr, stated:

I mean, some of the aftereffects I've lived with all my life and I've never known what to make of them. And I get, you know, I get these moments and experiences like we've had where I just go, "Oh, oh. That's why I've been feeling that way for the last 30 years." That's great. This is so cool.

Das, an 80-year-old non-NDEr and biologist, reported, "But I've just learned, if anything, that there are new questions that have been raised." Finally, Lil, an NDEr, said, "And listening to other members of the group, you know there was more of an understanding that no, really my experiences are very real. It's just that we don't tend to talk about things that are sort of not common."

The areas that participants learnt about others while listening during the group interactions included: similarity in, variety of, and a broader understanding of NDEs and their aftereffects, connection with others, the importance of networking, and an NDE "ideal" versus "real life" (or how things "should be" and the way they actually are). Daniel, a non-NDEr, spoke to the variation of experiences: "I was surprised to learn the breadth of variations in the experience." He further stated:

But beyond that, I was taken with the different places in the process of integration of the experience that the [NDErs] were. I was a little bit surprised, I guess because I had again expected that they would have processed it and come to the same place. And I don't know why I made that assumption, but that's definitely not true. And, ah, somehow that makes it more real or human for me.

Participants learnt about many areas when sharing their experiences within the group. Those areas mentioned included an increased awareness of own experience(s), increased self-awareness, the importance of sharing a fundamental part of oneself and not being "invisible," and for non-NDErs to express "resonance" with NDErs. Two other areas mentioned seemed to be two perspectives of the same discussion: first, learning to be vulnerable in the safety of a nonjudgmental group, and second, learning that the reason for suppressing oneself was the perceived judgment of others as well as not having social support or acceptance for one's experience. Luke, an 
NDEr, said of sharing, "Each time I tell it, it also does something; putting it out there verbally has that effect in a different kind of way." Lil, another NDEr, added, “... it was a very good experience to practice not being invisible." Although he did not have an NDE, Sammy spoke of his own vulnerability in the group and prior reluctance to share a spiritual mystical experience:

Feeling that I could be vulnerable and not judged and in safety because of the allegiance and the linkage of the group, having either interest or related experiences or understanding of, promoted more vulnerability coming out versus me sitting in a hot tub at the club and talking to someone who may have some peripheral interest.

He continued, "I think I've learned that I've repressed it, because, in a way, there wasn't a lot of cultural support or acceptance...."

Learnt from drawing. The theme learnt from drawing can be divided into two main categories: changes due to drawing and cognitive material learnt from drawing. Changes due to drawing can again be subdivided into five general categories: openings, connection, bringing back the experience, difficult start but became easier to draw, and increased personal growth and self-awareness. Lil, an NDEr, spoke most poignantly about the opening she experienced in the group.

I think the art, I did learn something specific because you know you sort of forced me to use that part of myself that I keep shutting, and I just realized that it was actually really fun. Not only fun, but that there was really I think a lot of value that could come of it.

Sammy, a non-NDEr, spoke of connection with other participants and about connections both internally and with something greater than himself: "[Drawing] frees me up to talk more about it because I have images to dialogue with that you can connect with, or others can connect with." He continued:

So the other advantage is I think that this connects with, by me drawing, connects with this other part of my being that acknowledges that this symbolic world, this communication to or imagination is very credible, and a mode of information gathering that we should honor. So it's almost like me praying by drawing. I'm praying and developing this phone line, if you will, with a spiritual dimension within my being or perhaps outside of my being.

Both Louis, a non-NDEr, and Charles, an NDEr, spoke about remembering their own experiences. Louis stated: 
Yea, it was more intense than I anticipated because it took me back to the experiences that I have had that were closest to the near-death experience. And those were very intense experiences, and so it felt like an intense thing to even get back a little bit into it.

Cognitive material learnt from drawing included realizing the possibility to see one's own inner process and emotions on external media, and that drawing was a different way of expressing an experience, allowed a lot of material (psychological, emotional, and spiritual) to come out quickly, provided new realizations about one's own experiences (NDE or other), and was another way of learning about and connecting with other participants. Charles, an NDEr, spoke of seeing his inner experience and then being able to reflect upon it:

One of the advantages was drawing the pictures 'cause you didn't, you know, it just comes out when you draw and your feelings come out and then you look at them later and that's, I guess that's where the benefits come out. How you see them. How it makes you feel. What it makes you think about.

Luke, another NDEr, added:

I was very hesitant about the drawing part of the sessions at first and really just took a leap of faith by showing up and to see what happened, and what happened was very surprising to me, very satisfying. I was able to feel very comfortable about how living whatever inner part of myself that I've had a hard time letting go in the past and put colors on my paper and formed some shapes and things. And not to worry about whether it fitted some preconceived idea of what was supposed to be there, and that is very liberating, very freeing and I mean, I'm very grateful for that, 'cause I feel like I can do more of that now... and I also feel like I got a sense of being able then to look at, you know, to externalize some of the things that I was holding inside or I'd been holding inside for so long and then to look at it. Then I can see the experience in a different way.

Lil, an NDEr, seemed amazed at the telling of her story through drawing: "And I was surprised that it actually told my story. It was a way of telling my story."

Changes because of the group. This theme, as all themes in this next section, was divided into two groups of responses: NDEr and nonNDEr themes. The NDEr themes included personal, psychological, and emotional changes (such as in close relationships, healing of painful memories, emotional release, and seeing life patterns), and 
new relationships, both within oneself, particularly around the NDE, and with others (desiring connection with other NDErs, and willingness to talk about and express the experience). Lila spoke directly to the topic of personal change: "I do feel more positive about myself, and my relationships with my family." Charles, when asked if anything had changed for him because of the group, responded, "relationships with people." Charles also spoke of his increasing comfort with his distressing NDE:

Made me feel a lot more comfortable because, I mean, I still felt the feelings as a seven-and-a-half-year-old kid, you know? And that was really scary. Thinking "oh my God. I'm outside of my body. I'm in big trouble. I'm in huge trouble. This is not where I wanna be. I don't like it here," you know? And it's like it's a lot easier after drawing the pictures, talking about it, hearing other people's stories, you know? That doesn't have to be the end.

Luke also reported both more willingness to talk about his experience and an increased ability to express his experience:

I think that the main thing that has changed for me is that I am just more willing to talk to people about the NDE experience ... and it's just, I'm so much more willing and ready and eager to talk about this stuff. And um, I am able to express it better.

Non-NDEr accounts of changes due to the group were categorized into three main areas: connection (both internally and externally), spiritual seeking, and generally having a new approach toward the NDE. An example of internal connection included Sammy's increased remembering of dreams. Louis provided an example of a combination of internal and external connection first by her awareness of her judgments and then by her desire to be less critical of others: "Well I must say that I am still redoubling my efforts to be less critical of others. I know it's always a projection, and so knowing that, one would think [that] I could withdraw my judgment. But I don't..." Pebble added, "I feel more open and moved by the stories that I heard ..." and, "I am so much more accepting of people." On the topic of spiritual seeking, Renata reported an increased desire in knowing her own purpose in life and a desire to hear more firsthand NDEs. Pebble also reported the most dramatic example of change attributed to the group, as demonstrated in the interview material: "I feel like a different human being after the group. I mean, feels like my words aren't even touching my experience. The experience was very profound for me, hearing those stories. And I just don't feel the same." 
Changes in perspective toward the NDE. NDErs' themes in regard to changes in perspective toward the NDE revolved around four main areas: expanded knowledge of NDEs, an increase in self-awareness, emotional transformation, and that the NDE provides spirituality. Lila spoke of expanded knowledge in terms of variety of the NDE: "I guess knowledge or hearing about others' experiences has made it more expansive for me." Luke spoke of the NDE as becoming less fragmented:

My own seems more real. It seems, it just seems more connected with the overall human experience, and I guess the bottom line of it all would be I feel more of its power and more in awe of it the more I feel it and the more I explore it and the more I communicate about it. It just, it's awesome. It's an awesome thing and it's been very fragmented for me over my life and I feel it's sort of starting to come together into a more unified experience.

Charles's group interview response targeted the area of self-identity that some of the participants reported feeling: "Yea, I feel like having a near-death experience definitely makes you know who you are and your weak[nesses] and your strengths and it's, you really don't have a problem being you, you know?" Lil added:

But the near-death experience is the experience that will help me the most of any experience that I have had in my life to know who I am. And to really, I think, become who I am. And to really become a much more authentic person.

Lil also noted the potential for emotional transformation through, as well as the spiritual nature of, the NDE:

But it seems to me that it's just one of the largest opportunities that we have in life to move in a significantly changed direction. And that, because it has such a spiritual aspect to it, that it can really bring you a lot of sense of calm and connectedness. It is like a knowing, almost.

Non-NDErs also reported an increase in their understanding of the NDE, feeling a connection with experiencers, and finding in NDEs confirmation for their own beliefs. Renata said, "I have never heard any from anyone else about, directly about the NDE other than reading books, and I felt, wow, this is real. I mean, it, it's not just a story... somebody did it for real." Pebble added:

I guess it went from not knowing a whole lot about it to having kind of a curiosity in a deep way, a deep curiosity to having sort of specific information like where I could actually define to somebody else what 
a near-death experience was. And then also this kind of a relationship with [pause] it's like something. It's like a new being has been created and I don't know, but I'm learning about it.

Das reported an increased sense of closeness to the NDErs: “... feel closer to them, to the people who have had it, as they describe theirs. You know, they've just established that it's kind of a bond."

New or unusual "stuff" that came up during the groups. This theme is primarily about memories, thoughts, feelings, ideas, and anything else that developed for the participants during the group meetings. NDErs and non-NDErs had basically the same categories arise from their interview material in this theme. Both groups reported hearing surprising new topics, having memories come back, feeling emotions rekindled, having personal psychological and emotional healings, and feeling the presence of spirit during the group meetings. Unusual or unexpected topics included the link between karma and responsibility (Renata, non-NDEr), the androgyny of spirit and masculine/ feminine nature of being (Luke and Lila, both NDErs), and psychic phenomena and kundalini (Pebble, non-NDEr), to name a few. NDEr Charles said of the raising of memories, "it just drug up old memories, what happened to me, where I was when it happened." Das, a non-NDEr, added that the process facilitated "seeing them [NDErs] in a slightly different light as a result." Regarding emotions, Charles (NDEr) said, "I didn't expect it to be that vivid once it came up and we started drawing the pictures ... as far as the feelings go." On a psychological and emotional level, Lila was surprised at the raising of filial material, "emotional stuff with my kids. Revisiting I guess feelings about my parents...." Lil gained an awareness that "I'm not invisible in all situations, but I am invisible in areas that are particularly sensitive to me or have a lot of meaning to me." Sammy, a non-NDEr, noted the group link to the heart in our last session of the second group, most of us having drawn a heart of some sort, and its spiritual implications of group connection and heart as a spiritual center. Additionally on the topic of spirituality, Luke (NDEr) mentioned that "what was unexpected is how the boundaries seem to be getting much more porous and the veil is much more transparent."

However, there were two differences between the subgroups. One NDEr, Luke, mentioned the unexpectedness of the interest of a nonNDEr: "a new thing would be that there was a non-experiencer there who really seemed to be able to follow a lot of what was being said and 
really contributed." Conversely, and in another group, a non-NDEr (Daniel) noted his own surprise at his willingness to share: "I surprised myself by talking about what occurred with my brother ... because I had never talked about it, so, unexpected."

\section{Qualitative Picture Results}

After my initial in-depth analysis of the elements of the pictures (see Rominger, 2004 for elements present in the pictures and comparison of various subgroups' pictures), the photographs were then compared between NDErs and non-NDErs. NDErs tended to depict a process of change. However, this process was implicitly built into the session structure with topics starting with the NDE, proceeding to the aftereffects, and ending with current feelings toward the experience. Pleasurable NDErs also drew the light and its particular characteristics, usually using glitter paints. The distressing NDEr (dNDEr) drew aspects of physical loss after the accident, but he was also the only NDEr with major physical trauma leading to loss of function of part of his body. All pleasurable NDErs used rainbow colors in their drawings and more abstract images, whereas the dNDEr depicted views of scenes. All NDErs drew some aspect of the light coming into themselves in the picture or the picture more generally, facilitating change in some form, usually from darkness into a lighter, more colorful area. All NDErs that drew in the last session (in which the topic was an overview of all sessions and how the participant currently felt about the NDE) drew hearts in the picture, possibly implying a more "heartfelt" connection to the NDE and the group members after the small group meetings.

Non-NDErs had a wider variety of picture themes, which made summarization of this subgroup more difficult. Non-NDErs seemed to have more pictures depicting an internal process of self-discovery or change. Four participants depicted their own exceptional human experiences, whereas three drew a process linked specifically to the overt content of the group sessions. Two individuals who had similar mystical experiences, yet participated in different groups, drew similar pictures including crystals, light beings, and radiating motifs, and both individuals used purple in the last session for the main color. One participant had another type of mystical or exceptional experience, which included reported precognition of a brother's death, which he drew. Another non-NDEr drew what reportedly 


\section{Table 1 \\ Resonance Panel Themes}

NDE Panel

1. Connectedness/ connection

2. Self-discovery/ awareness/change in perception/process/ aliveness

3. Love-heart-feelingemotion

4. Individual is different yet the same, the same yet different

5. Omnipotent type of being/source

6. Motion-energy-love

Spiritual Guidance Panel Expressive Arts Panel

1. Transformation, including movement and integration, from the individual outward to others, beyond the microcosm

2. Healing and wholeness, from individual outwards/ beyond the self

3. Transformation of self through contact with the numinous

4. Reflection on process of contact with one's woundedness

5. Potential/openness

6. Difference in where one is at in the psychospiritual process
1. Circular patterns (birth canals, eye images)

2. Symbols, such as the heart

3. Symbols of life, growing plant/ growth/life, depictions of nature

4. Energy moving out, radiating outward from center

5. Rainbow colors, vibrant, colorful (lack of black and white pictures)

6. Progressed from disturbance/disorder into less disturbance/more ordered/balance/ sense of self in relation to other things, integration/ union, pulled together pieces/ parts into cohesion/ balance by the end 


\section{Table 1 \\ (Continued)}

NDE Panel

Spiritual Guidance Panel Expressive Arts Panel

7. Spirituality \& religious symbols

8. Duality
7. Last class had a lot of blue, red, purple, vibrancy, rainbow colors

8. Connection to spirituality

9. Organic (formless life energy)

turned out to be an empathic NDE that she had a few years prior to the study.

After my initial analysis, I held the resonance panels. The NDE resonance panel, which consisted of two male NDErs who had their NDEs 18 and 22 years prior, were 48 and 37 years of age, and classified themselves as Christian mystic and spiritualist, was held at the Institute of Transpersonal Psychology over a two-hour period. The spiritual guidance resonance panel consisted of three females who were professional spiritual directors. Because the topic of NDEs was not discussed until after this panel answered all questions, no information was specifically gathered about presence of NDEs or experience with the topic; however, members expressed several strong reactions during the meeting as they resonated with particular pictures. The spiritual guidance panel was held at a local spiritual retreat center and lasted approximately two hours. The Expressive Arts panel consisted of three female expressive art therapists and/or expressive artists. One panel member had obtained a doctorate in psychology and was a practicing therapist, the second had obtained a master's degree in clinical psychology and was practicing, and the third was a graduate student in a psychology master's (MFT) program and had engaged in the expressive arts for her own growth and development. This last panel was held at the Institute of Transpersonal Psychology and lasted approximately two hours. Themes that emerged from the resonance panel meetings are provided in Table 1. 


\section{Discussion}

\section{Quantitative Data and Results}

Due to the small $N$ in this study, the results should be viewed as tentative, yet provocative for future research. Results largely indicated a trend toward change within the study's population. Patterns of increased attitudes and beliefs (appreciation of life, concern for others, and quest for meaning) generally followed those trends of NDEr change noted in prior research, and as one area increased so did the others. Similarly, patterns of decreased attitudes and beliefs (concern for the material things in life, interest in creating a "good impression," fear of death, desire to become a well known person) mimicked patterns demonstrated by NDErs.

Another interesting pattern involved comparison of NDErs and nonNDErs. At the start of the study, NDErs indicated greater increases since their NDEs than non-NDErs indicated since 28 years before, in the areas of "understanding what life is all about," "having a sense of the sacred aspect of life," and "acceptance of others." At first posttest, NDErs again indicated greater increases in the areas of "feelings of intimate connection and unity with a partner during sexual encounters," "tendency to pray," and "interest in self-understanding." However, by the longitudinal posttest, the two groups did not differ. This finding may indicate a homogenization within the groups, with non-NDErs and NDErs having some effect upon each other, possibly influencing each other's attitudes and beliefs in these areas.

Regarding participants' overall level of spirituality, participants were initially similar in score to what one might find within the general public. However, participants demonstrated rather high levels of spirituality after completion of the groups. This finding remained strong even at the longitudinal posttest. It would seem that the process of group spiritual guidance and expressive arts described in this study was similar to, in effect, that of a long-term group focused on spiritual development. Additionally, three specific questions demonstrated an initial increase after completion of the groups, but a subsequent decrease once the groups stopped. These three questions were "a sense of connection with other living things," "finding meaning in life by creating close relationships," and "reading articles on health and inner peace." It may be that contact with the group members and group process elevated these areas, but once contact ceased, attitudes toward these areas change back to what they were 
before the group meetings. This finding in particular raises the question: Would continued participation in a group process such as the one in this study be required for maintaining high levels on the items mentioned above? If so, for how long?

Combining the main results from the life change questionnaire and the spirituality questionnaire, not surprisingly many of the findings related to interconnection and relationships, which may have been one effect of being in a group format. Why some relational areas remained strong while others did not is unknown; however, it may be connected to a more permanent shift in participants toward compassionately opening and listening more to others, whereas the areas that decreased were more specifically relational in nature.

Experimenter bias and demand characteristics. In the current study, I did not actively try to reduce my experimenter bias through the use of expectancy control groups. As a spiritual guide, I did expect my participants to become more spiritual in some form, although I was unsure how this increase might manifest in participant responses for particular items on the two quantitative instruments I used. This situation might be compared to the Pygmalion study Rosenthal (2002) reported, whereby students of teachers who expected students to be bright scored higher on IQ tests at the end of the school year. As a spiritual guide, I do not see expectation as a problem; it is part of the guide's responsibility to hold and respect clients in their highest spiritual nature. However, as both spiritual guide and researcher, it is quite possible that I conveyed unforeseen experimenter bias that played a role in the results reported above.

Demand characteristics may have also played a role in statistical outcome. Part of the design of the present study was that participants would attend a group meeting that was held within a spiritual context. Part of this context included a spiritually-oriented center piece, candles in almost every session, and meditation or centering during sessions. These contextual elements may have provided demand cues to participants implying they should respond within the group from a spiritual perspective, and that was exactly the intent of using those elements. However, some critics may view these actions as potential biasing demand characteristics that signaled participants to exaggerate their responses to reflect greater spirituality than they actually experienced.

Another specific example of potential extraneous variable influence was that of increased compassion and listening to others. This aspect, and quite possibly other specific aspects found in the results, may not be due solely to discussing and drawing the NDE in a small group 
format. Three other extraneous variables may have been: (a) simple participation within a powerful group setting, (b) cathexis/catharsis around an important personal topic, or (c) my "charm" and personality as a facilitator. It is possible that an interaction effect among the variables contributed to various findings, including increased compassion and listening to others. It was to allay this concern as much as possible that I included qualitative methods in this study. Through the interview material and pictorial material one may conclude that the content and process of the small groups did indeed play an important role in determining participant results.

\section{Qualitative Interview Data and Results}

Interview data supported and expanded upon the quantitative results. For example, communality - connection with others, compassion toward others, and empathy and understanding of others' NDEs or similar experiences - characterized items demonstrating increase in the spirituality and life changes instruments and also emerged as one of the largest themes that I found in the interview material and that the resonance panels cited. In addition, from drawing, sharing, and listening to others share, participants reported learning in four additional areas: emotionally (healing family pain, healing negative emotions around NDE, and accessing positive emotions around NDE), cognitively (content learning about the NDE and its aftereffects), spirituality (compassion for others, connection to other living things, and healing religious wounding), and artistically (that drawing can elicit and depict internal states, that drawing brings forth emotion, and that drawing was not as difficult as first perceived).

These results may be viewed in light of Kelly's (1995) description of two processes found in therapeutic settings that incorporate spirituality: the rethinking/re-experiencing process and the applying and enhancing process. First, through the rethinking/re-experiencing process NDErs became aware of their beliefs; reframed them if appropriate, especially if still trying to partition off the experience from their lives; considered an alternative language with which to speak about the NDE; and revitalized the positive aspects of the experience by bringing it back into conscious memory. The application process helped the NDErs to apply existing beliefs and practices that have come into existence since the experience, and the enhancing process allowed the NDErs and guide to bring forth hidden qualities within the experience(r). 
Non-NDErs also benefited from this process. Non-NDErs had the ability to witness the NDErs' processes, and thus questioned and investigated their own beliefs, reframed existent beliefs, relabeled their own beliefs and experiences, and revitalized positive cognitions and emotions around the near-death phenomena. The non-NDErs also applied (or confirmed) their own beliefs in their lives and enhanced beliefs that might have been dormant, hidden, or underemphasized.

\section{Qualitative Picture Data and Results}

Pictures were divided dependant on presence or absence of an NDE. This finding may have been the most dramatic, considering NDErs tended to draw the transformation that they went through following the experience. The dNDEr drew aspects of the physical outcome from his accident but moved beyond these drawings into depicting a changed perspective, growing into a person with heart, and seeing both the light and darkness of life. All pleasurable NDErs, which is the prototypic "core" NDE most common in the literature, used rainbow colors and used more abstract images to depict aspects of light, the NDE, and its aftereffects. All NDErs drew some aspect of light, whether it was a recent addition into life as in the case of the dNDEr or an infusion of light during and after the experience for pleasurable NDErs. Surprisingly, all NDErs drew hearts in the last session. This finding implies that the NDErs currently had a positive relationship to their experience and, quite possibly, to the group sessions.

The resonance panels added external confirmation and validation of themes that emerged within the pictures participants drew. The NDE panel themes coincided with the quantitative and qualitative interview material results, naming as pertinent themes connection, self-awareness, and spirituality and religious symbols. The spiritual guidance panel reported more themes on transformation, movement, openness, healing, and internal processes such as contact with one's own woundedness. The expressive arts panel focused on colors and visual patterns such as circular patterns, symbols of the heart, symbols of life and growth, rainbow colors, and the vibrancy and colors within the last session. The expressive arts panel also identified process themes including energy moving outward/radiating outward from center, progression from disorder to order, progression from disturbance into balance/integration, and connection to spirituality. This panel also noted the presence in the pictures of an organic 
formless life energy being depicted. The three panels independently agreed that some change, movement, or transformation had occurred. These themes once again seemed to confirm the healing and transformative nature of group spiritual guidance and expressive arts for the participants.

\section{Implications for Psychologists, Spiritual Guides, and Expressive Artists}

The small group format described in this study, including group spiritual guidance and expressive arts, provided an adequate format for NDErs who could benefit from further integrating their experiences. NDErs demonstrated significant changes, some from a statistical perspective but more from a personal perspective, that helped them to understand more fully the aftereffects and accept the changes that had happened since the experience. This finding was amazing to me considering all but one NDEr had their experiences over 30 years prior. The one NDEr who had recently had her experience stated that the group was timely and gave her a context for thinking about and describing her experience. She also reported that the small group meetings assisted her individual therapy process. Thus, a small group experience such as the one described herein appears to be potentially beneficial both shortly after and long after an NDE.

Considering the NDE is one type of spiritually transformative experience (Kason \& Degler, 2000), the process described herein may also facilitate integration of other potentially spiritually unsettling and growth-facilitating phenomena. In fact, it is possible that many phenomena under the DSM-IV-TR classification of V62.89 Religious or Spiritual Problem (DSM-IV-TR, 2000) could be addressed using this group format, depending on client preference and personality style. It may not be appropriate with individuals who would not prosper in a group setting, who have a comorbid diagnosis that would make it difficult for them to participate in the inner work practiced in spiritual guidance or expressive arts, or who are particularly strict or proselytizing in religious beliefs. However, these clients aside, many individuals with religious or spiritual problems may prosper within group spiritual guidance and expressive arts.

Another difficulty that therapists, spiritual guides, and expressive artists must be aware of is the response of one of the individuals who dropped the study. She reported that her participation, and it seemed 
Table 2

Summary of Contributions

\section{Spiritual Guides/Directors Expressive Artists Clinical Therapists}

1. Group guidance and creative expression combined can help individuals integrate NDEs and other spiritually transformative experiences.

2. Integration can help facilitate increased spirituality.

3. It seems vital that experiencers are given the chance to convey an experience in multiple ways.

4. Open, not dogmatic, context vital for open communication.

5. Creating a spiritual context for discussion facilitates discussion of exceptional experiences.
1. Have many 1. Whatever the cause, media available NDEs and similar for expression. experiences are associated with powerful memories and emotions.

2. Have glitter paint and other light/texture media for depiction of transpersonal experiences.

2. Be open to discussing rather than dismissing the potential reality of the NDE.

3. Group spiritual guidance and expressive arts may help individuals with V62.89 Religious or Spiritual Problem.

memories associated with the experience.

4. Allow space to 4. It is helpful for NDErs share pictures created as this allows a way of further communicating the experience to others in the group.

5. Art is a valid means of research and can add validity to other methods of research. to share their experience and listen to others share their experiences, particularly within a Rogerian, clientcentered setting.

5. Creative expression is useful for eliciting ineffable experiences. 
to me as facilitator that her producing the expressive arts, brought up too many emotionally laden childhood memories. Due to small sample size it is not possible to know if her response is anomalous or if she indeed represents roughly one-tenth of a clientele population that may seek out self-enhancing groups focused on the topic of NDEs. If her response is typical in this manner, then facilitators should be aware that some clients may not be emotionally suited or ready to reveal within a small group setting as described within the present study. At the present time it is unknown how one might screen individuals who potentially fall within this category, except possibly through an interview process that directly addresses whether the individual is overly hesitant to open emotionally within a small group.

A summary of contributions to spiritual guides and directors, expressive artists, and therapists who work with, or are considering or planning to work with, NDErs appears in Table 2.

In conclusion, a small group led by a spiritual guide, expressive artist or art therapist, or a mental health professional competent in spiritual guidance and expressive arts may hold promise for both NDEr and non-NDEr clients seeking change similar to what NDErs typically report. Hopefully future researchers will continue to study the trend phenomena demonstrated within the present study.

\section{References}

American Psychiatric Association. (2000). Diagnostic and statistical manual of mental disorders (4th ed., text revision). Washington, DC: Author.

Anderson, R. (1998). Intuitive inquiry: A transpersonal approach. In W. Braud, and R. Anderson (eds.), Transpersonal research methods for the social sciences: Honoring human experience (pp. 69-94). Thousand Oaks, CA: Sage.

Anderson, R. (2000). Intuitive inquiry: Interpreting objective and subjective data. Revision, 22(4), 31-39.

Bechtel, L. J., Chen, A., \& Pierce, R. A. (1992). Assessment of clergy knowledge and attitudes toward near-death experiences. Journal of Near-Death Studies, 10, 161-170.

Bush, N. E. (1991). Is ten years a life review? Journal of Near-Death Studies, 10, 5-9.

Clark, K. (1987). Response to "Adjustment and the Near-Death Experience." Journal of Near-Death Studies, 6, 20-23.

Devereux, J. M. (1995). Living life after encountering the light: A phenomenological exploration of the meaning of a near death experience. Unpublished doctoral dissertation, The Union Institute, Cincinnati, OH. (UMI/ProQuest AAT No. 9529106)

Dougherty, C. M. (1990). The near-death experience as a major life transition. Holistic Nursing Practice, 4(3), 84-90.

Famighetti, R. et al. (eds.). (1999). The world almanac and book of facts 2000. Mahwah, NJ: World Almanac Books.

Furn, B. G. (1987a). Adjustment and the near-death experience: A conceptual and therapeutic model. Journal of Near-Death Studies, 6, 4-19. 
Furn, B. G. (1987b). Cross-cultural counseling and the near-death experience: Some elaborations. Journal of Near-Death Studies, 6, 37-40.

Gallup, G., Jr. (with Proctor, W.) (1982). Adventures in immortality. New York, NY: McGraw Hill.

Greyson, B. (1983). The near-death experience scale: Construction, reliability, and validity. Journal of Nervous and Mental Disease, 171, 369-375.

Greyson, B. (1986). Incidence of near-death experiences following attempted suicide. Suicide and Life Threatening Behavior, 16(1), 40-45.

Greyson, B. (1991). Near-death experiences and systems theories: A biosociological approach to mystical states. Journal of Mind and Behavior, 12, 487-507.

Greyson, B. (1992). Reduced death threat in near-death experiencers. Death Studies, 16 , $523-536$.

Greyson, B. (1993b). Near-death experiences and antisuicidal attitudes. Omega: Journal of Death and Dying, 26(2), 81-99.

Greyson, B. (1994). Near-death experiences and satisfaction with life. Journal of NearDeath Studies, 13, 103-108.

Greyson, B. (1996). The near-death experience as a transpersonal crisis. In B. W. Scotton, A. B. Chinen, and J. R. Battista (eds.), Textbook of transpersonal psychiatry and psychology (pp. 302-315). New York, NY: BasicBooks.

Greyson, B. (1997, May). The near-death experience as a focus of clinical attention. Journal of Nervous and Mental Disease, 185, 327-334.

Greyson, B. (2000). Near-death experiences. In E. Cardeña, S. J. Lynn, and S. Krippner (eds.), Varieties of anomalous experience: Examining the scientific evidence (pp. 315-352). Washington, DC: American Psychological Association.

Greyson, B., \& Bush, N. E. (1992). Distressing near-death experiences. Psychiatry: Journal for the Study of Interpersonal Processes, 55(1), 95-110.

Greyson, B., \& Ring, K. (2004). The Life Changes Inventory - Revised. Journal of NearDeath Studies, 23, 41-54.

Grosso, M. (1981). Toward an explanation of near-death phenomena. Anabiosis: The Journal for Near-Death Studies, 1, 3-25.

Groth-Marnat, G., \& Summers, R. (1998). Altered beliefs, attitudes, and behaviors following near-death experiences. Journal of Humanistic Psychology, 38(3), 110-125.

Hardy, D. S. (2000). A Winnicottian redescription of Christian spiritual direction relationships: Illustrating the potential contribution of psychology of religion to Christian spiritual practice. Journal of Psychology and Theology, 28, 263-275.

Hayes, E. R., \& Waters, L. D. (1989). Interdisciplinary perceptions of the near-death experience: Implications for professional education and practice. Death Studies, 13, $443-453$.

Hervey, L. W. (2000). Artistic inquiry in dance/movement therapy: Creative alternatives for research. Springfield, IL: Charles C. Thomas.

Kason, Y., \& Degler, T. (2000). A farther shore: Exploring how near-death, kundalini and mystical experiences transform ordinary lives (rev. ed.). Toronto, Canada: Harper Collins.

Kellehear, A. (1990). The near-death experience as status passage. Social Science and Medicine, 31, 933-999.

Kellehear, A., Heaven, P., \& Gao, J. (1990). Community attitudes toward near-death experiences: A Chinese study. Journal of Near-Death Studies, 8, 163-173.

Kelly, E. W., Jr (1995). Spirituality and religion in counseling and psychotherapy: Diversity in theory and practice. Alexandria, VA: American Counseling Association.

Ketzenberger, K. E., \& Keim, G. L. (2001). The near-death experience: Knowledge and attitudes of college students. Journal of Near-Death Studies, 19, 227-232.

McDonagh, J. (1987). Review of Bette Furn's "adjustment and the near-death experience." Journal of Near-Death Studies, 6, 24-27.

McNiff, S. (1989). Depth psychology of art. Springfield, IL: Charles Thomas. 
Mellick, J. (1996). The natural artistry of dreams. Berkeley, CA: Conari Press.

Miller, J. S. (1987). A counseling approach to assist near-death experiencers: A response to Bette Furn's paper. Journal of Near-Death Studies, 6, 30-36.

Moody, R. A., Jr. (1975). Life after life. New York: Bantam Books.

Moody, R. A., Jr. (1999). The last laugh. Charlottesville, VA: Hampton Roads.

Musgrave, C. (1997). The near-death experience: A study of spiritual transformation. Journal of Near-Death Studies, 15, 187-201.

Moustakas, C. (1990). Heuristic research: Design, methodology, and applications. Newbury Park, CA: Sage.

Packer, M. J., \& Addison, R. B. (1989). Evaluating an interpretive account. In M. J. Packer, and R. B. Addison (eds.), Entering the circle: Hermeneutic investigation in psychology (pp. 275-292). Albany, NY: State University of New York Press.

Parnia, S., Waller, D. G., Yeates, R., \& Fenwick, P. (2001). A qualitative and quantitative study of the incidence, features and aetiology of near death experiences in cardiac arrest survivors. Resuscitation, 48, 149-156.

Ring, K. (1980). Life at death: A scientific investigation of the near-death experience. New York, NY: Quill.

Ring, K. (1984a). Heading toward omega: In search of the meaning of the near-death experience. New York, NY: William Morrow and Company.

Ring, K. (1984b). Further studies of the near-death experience. In B. Greyson, and C. P. Flynn (eds.), The near-death experience: Problems, prospects, perspectives (pp. 30-36). Springfield, IL: Charles Thomas, (Reprinted from Theta, 7[2], 1-3)

Ring, K. (1995). The impact of near-death experiences on persons who have not had them: A report of a preliminary study and two replications. Journal of Near-Death Studies, 13, 223-235.

Ring, K., \& Valarino, E. E. (1998). Lessons from the light: What we can learn from the near-death experience. New York, NY: Insight Books.

Rogers, N. (1993). The creative connection: Expressive arts as healing. Palo Alto, CA: Science \& Behavior Books.

Rominger, R. (2004). Exploring the integration of the aftereffects of the near-death experience: An intuitive and artistic inquiry. Dissertation Abstracts International, 65(04), 2110B, (UMI/ProQuest AAT No. 3129588)

Rosenthal, R. (2002, November). Covert communication in classrooms, clinics, courtrooms, and cubicles. American Psychologist, 57, 839-849.

Royse, D. (1985). The near-death experience: A survey of clergy's attitudes and knowledge. Journal of Pastoral Care, 39(1), 31-42.

Sabom, M. B., \& Kreutziger, S. (1977). The experience of near death. Death Education, 1, 195-203.

Sutherland, C. (1989). Psychic phenomena following near-death experiences: An Australian study. Journal of Near-Death Studies, 8, 93-102.

Tiberi, E. (1993). Extrasomatic emotions. Journal of Near-Death Studies, 11, 149-170.

U.S. Census Bureau. (2006). http://www.census.gov/ipc/www/usinterimproj/

Walker, B. A., \& Russell, R. D. (1989). Assessing psychologists' knowledge and attitudes toward near-death phenomena. Journal of Near-Death Studies, 8, 103-110.

Weisstein, E. W. (2004). "Bonferroni Correction." From MathWorld-A Wolfram Web Resource. http://mathworld.wolfram.com/BonferroniCorrection.html.

Wheat, L. W. (1991). Development of a scale for the measurement of human spirituality. Unpublished doctoral dissertation, University of Maryland College Park. (UMI/ ProQuest AAT No. 9205143)

White, P. R. (1997). The anatomy of a transformation: An analysis of the psychological structure of four near-death experiences. Journal of Near-Death Studies, 15, 163-185. 